\title{
Auxetic Cellular Materials - a Review
}

\author{
Nejc Novak* - Matej Vesenjak - Zoran Ren \\ University of Maribor, Faculty of Mechanical Engineering, Slovenia
}

Auxetic cellular materials are modern materials which have some unique and superior mechanical properties. As a consequence of the structural deformation of their internal cellular structure they exhibit a negative Poisson's ratio, i.e. they significantly increase in volume when stretched and vice versa. The effect of negative Poisson's ratio is useful in many applications to enhance certain physical properties such as the density, stiffness, fracture toughness, energy absorption and damping. These properties can be further tailored by using variable cell geometry and density distribution, which can be achieved with functionally graded porosity of auxetic materials. This review paper provides the state-of-the-art overview of the auxetic materials, their development, most common geometries, fabrication methods, mechanical properties, applications and further possibilities for their development.

Keywords: cellular materials, auxetic materials, negative Poisson's ratio, honeycombs, composites

Highlights

- Development, geometries, fabrication methods of auxetic cellular materials are presented.

- Identification and comparison of mechanical properties of different types of auxetic materials.

- Applications of auxetic materials are introduced.

- Possibilities for further development of graded auxetic cellular materials are indicated.

\section{INTRODUCTION}

Cellular materials have some advantageous mechanical and thermal properties in comparison to solid materials [1], for example: low density, high acoustic isolation and damping, better thermal management (for use in heat exchangers, flame arresters, heat shields), high energy absorption capabilities (for crash absorbers), durability at dynamic loadings and fatigue, filters etc. The production methods of cellular materials are described in [2] and [3]. Some cellular materials are being used in practical applications [4], but most of them were only investigated by experiments and simulations [5] to [8]. This is due to high production costs and a lack of mass production capabilities to control the shape, size and distribution of cellular pores during the production process which results in a certain scatter of mechanical properties. Novel uni-directional structures, such as lotus-type [7] and UniPore [8] materials, hollow sphere structures [9] and [10] and APM elements [11] to [13] were introduced recently, and comprehensively characterised. The new additive manufacturing technologies offer improvements in the production of cellular structures with constant or graded porosity.

The internal structure of cellular materials can also be designed so that its deformation results in a negative Poisson's ratio behaviour. Poisson's ratio $(v)$ is defined (in case of tension loading) as the ratio between the longitudinal expansion and the lateral contraction of material during the loading [14]. Materials that exhibit negative Poisson's ratio become wider when stretched and thinner when compressed (Fig. 1), and are also called the auxetic materials [15].

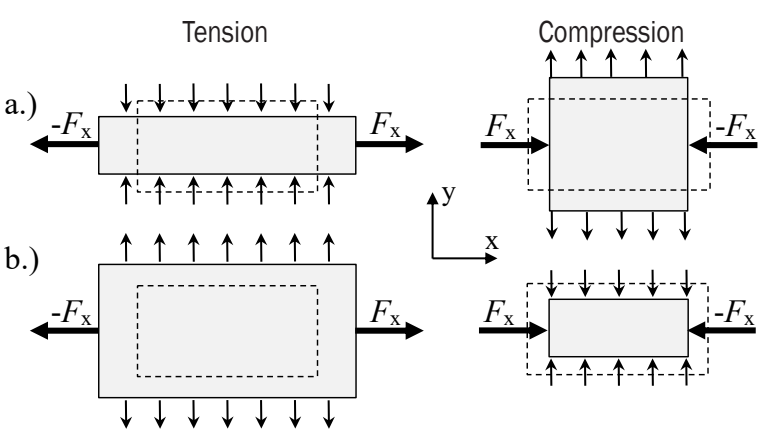

Fig. 1. Non-auxetic a) and auxetic b) behaviour during tensile and compressive loading (dashed lines - undeformed geometry)

This paper provides a short review of the development, geometries, manufacturing methods, mechanical properties and applications of cellular auxetic materials. Future prospects for further development and new applications of cellular auxetic materials are also discussed.

\section{AUXETIC MATERIALS}

The term "auxetic materials" was first introduced by Evans et al. in 1991 (from the Greek auxetos: that may be increased) [15]. The natural auxetic material can be found in $\alpha$-cristobalite [16], biological tissues (skin) 
[17] and pyrolytic graphite [18]. Man-made material structures with similar behaviour were first used in practical application as moderator core of a Magnox nuclear reactor [19], where auxetic behaviour occurs due to radial movement of the free-standing columns of graphite bricks via sliding of the loose keys. The structure was designed to withstand horizontal forces generated during earthquake, whilst also allowing free movement of the structure to accommodate thermal movements between the graphite core and steel supporting structures at the edges of the core. Development of this structure was conducted to solve a practical problem and auxetic behaviour was only a by-product of the design.

Systematic research of auxetic materials first started in 1985 with analysis of a 2D re-entrant auxetic structure by Almgren [20] based on analytical expressions presented a few years earlier for conventional honeycombs [21]. In 1987 first auxetic material was manufactured by Lakes and co-workers with transformation of conventional open cell foam [22]. Auxetic structures from polymers were also fabricated later [23] to [25]. Further progress was made by introducing composite structures that exhibit negative Poisson's ratio [26]. Next promising way to produce cheaper, more complex and larger auxetic structures is additive manufacturing.

It is not always necessary to have a porous microstructure (like in cellular materials) to induce the auxetic behaviour of the material structure [26]. The change in microstructure (molecular auxetic materials) or composite structures with rotating units can also exhibit the auxetic behaviour [27].

However, most of above mentioned auxetic structures are highly anisotropic and thus not well suited for the general structural applications in most cases. For this reason, a very exciting development of novel 3D cellular auxetic materials is being investigated at several research centres around the world and we can expect some promising auxetic materials to emerge soon.

Most of auxetic materials can be classified into three main groups: auxetic honeycombs, auxetic microporous polymers and auxetic composites. Auxetic materials which do not belong to any of these groups are also described in Section 1.4.

\subsection{Auxetic Honeycombs}

Conventional and auxetic honeycomb 2D structures are the most common types which have been investigated widely over past few decades. These 2D structures can be extended in the normal direction to get a 3D unidirectional auxetic structure.

\subsubsection{Re-entrant Structures}

Development of 2D re-entrant honeycombs (Fig. 2) started with analytical calculations of various deformation mechanisms caused by flexing the cell walls [20] or more realistic behaviour when honeycombs undergo flexure, stretching and hinging deflections when subjected to external loadings [28].

a)

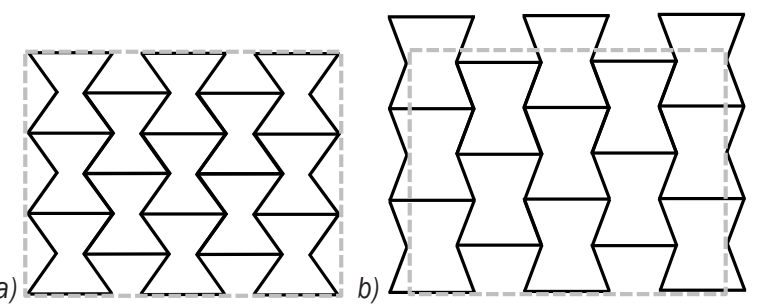

Fig. 2. a) Undeformed and b) deformed re-entrant structure

\subsubsection{Rotating Units}

Auxetic structures with rotating units were presented by Grima and Evans [27], where rigid rectangular and triangular cells are connected together at selected vertices by hinges (Fig. 3). These kinds of structures result in analytical value of minus one for the Poisson's ratio. The auxetic behaviour of the rotating units was analysed with analytical expressions for the rotating rectangles [29] and [30] and the triangles [27]. Semirigid rotating units were also developed [31]. Real structures with similar behaviour as the rotating units (square array with elliptical voids) were analysed with experimental testing and numerical simulations [32].
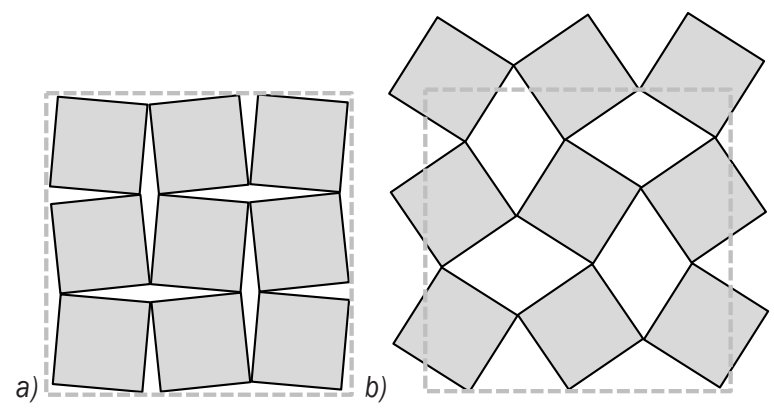

Fig. 3. a) Undeformed and b) deformed rotating rectangles

\subsubsection{Missing Rib}

Missing rib structure is derived from conventional honeycomb (intact) where cutting of some ribs (Fig. 
4) leads to the auxetic behaviour [33]. Experimental testing of two different missing rib structures and two conventional structures was done by Gaspar et. al [34].

a)
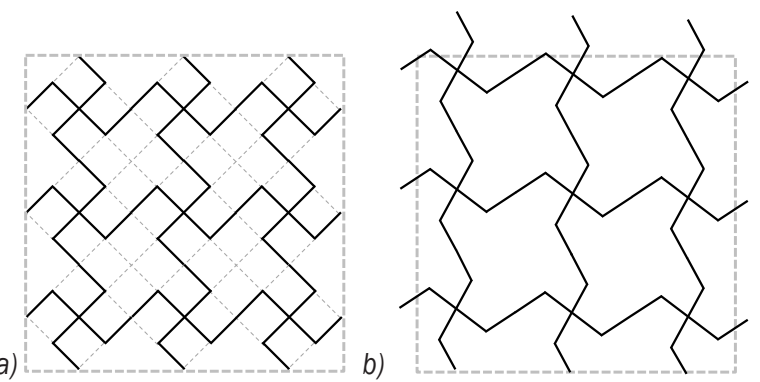

Fig. 4. a) Undeformed and b) deformed missing rib structure (dashed lines-intact conventional structure)

\subsubsection{Chiral Structures}

Chiral structures are formed by connecting straight ligaments (ribs) to central nodes which may be circles or other geometrical forms (Fig. 5). The auxetic effects are achieved through wrapping or unwrapping of the ligaments around the nodes in response to the applied force. Poisson's ratio of chiral structures is -1 , based on theoretical and experimental investigation [35].
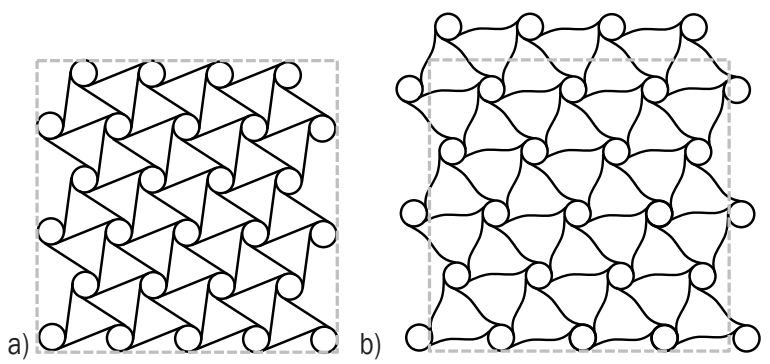

Fig. 5. a) Undeformed and b) deformed chiral structure

\subsubsection{Other Honeycomb Geometries}

Many other auxetic geometries were also developed in the past: antichiral structures with different strategies of connecting central nodes [36], star [37] and double arrowhead [38] structures, 2D planar structures using Kagome patterns [39] and [40]. Geometry of auxetic honeycombs was also developed with numerical analysis of eigenvalues and natural frequencies of different non-auxetic honeycombs [41].

\subsection{Auxetic Microporous and Molecular Polymers}

After successful production of auxetic material from conventional polymer foam [22] researchers were looking for procedure with which they can fabricate stiffer materials for wider engineering applications. Structure from expanded polytetrafluoroethylene (PTFE) was produced and evaluated by tensile testing methods [23] and [24]. Extremely low negative Poisson's ratio values up to minus 12 in one direction were achieved and explained by the anisotropic foam structure. A simple concept to explain the complex microstructure deformation behaviour found in auxetic PTFE is shown in Fig. 6, where hatched regions are nodules. Further experimental testing and deformation mechanism analysis was done by Alderson and Evans [42] and Alderson et al. [43].

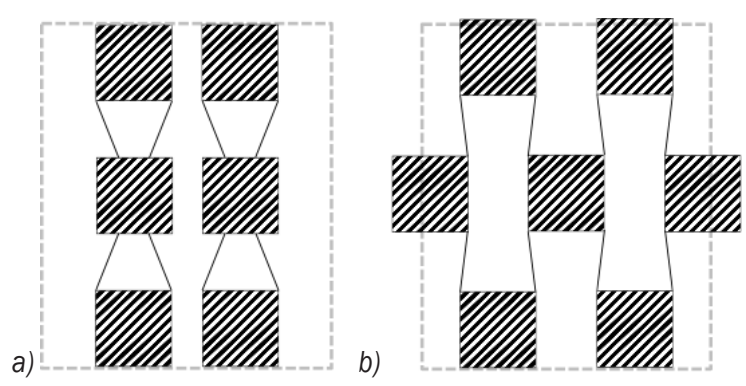

Fig. 6. a) Undeformed and b) deformed nodule-fibril model network

Similar microporous polymer microstructures can be produced using the ultra high molecular weight polyethylene (UHMWPE), with some distinct differences: nodules in UHMWPE are nearly spherical and the structure is more isotropic. These differences also influence the Poisson's ratio which for UHMWPE is no lower than minus 1.24 [25].

Researchers have also observed that the auxetic behavior of some of the polymer structures is not depend on the scale of the material [44], which is convenient for production of larger specimens and components.

Microporous auxetic polymers possess auxetic properties because their porous structures allows sufficient space for the nodules to spread apart. But this porosity leads to lower density and stiffness values resulting in their unsuitability in many structural applications.

One approach to overcome the problem with material porosity is to develop molecular auxetic material, where the molecular structure is tailored to exhibit negative Poisson's ratio [45] and [46]. Tailoring is done by inserting molecular elements which causes the auxetic behaviour in the molecular structure. However, many problems in synthesizing and testing these materials still need to be overcome [15]. In the future, when synthesizing methods improve and allow for the development of anisotropic molecular auxetic 
materials, these kinds of materials could well turn out to be the best auxetic materials for use in structural applications.

\subsection{Auxetic Composites}

Composite materials are made of two or more different components with different material properties. Composite rod and hinge structures were first analytically investigated by Milton [26]. The model is shown in Fig. 7, where under infinitesimal deformations in the increase in the width $\mathrm{AB}$ causes an increase in the length $\mathrm{CD}$. If a series of these models are stacked together vertically in a matrix, a composite laminate with negative Poisson's ratio is obtained.

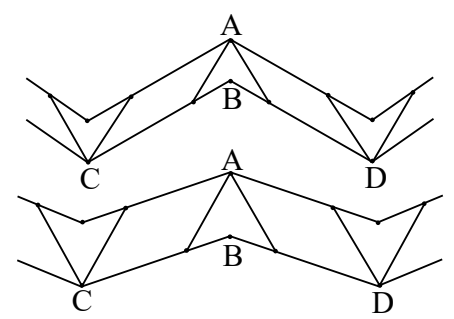

Fig. 7. Rod and hinge model

Auxetic composites can also be prepared by laminating unidirectional pre-preg tapes of epoxy resin reinforced with carbon fibers [47], or using fibrereinforced Poly-Ether-Ether-Ketone (PEEK), which are then bonded together in the triangular auxetic core [48].

Composite sandwich panels which employ cellular auxetic material as a core can also be useful for applications in the aerospace industry [49].

\subsection{Other Auxetic Geometries}

Many other 2D auxetic geometries were developed and analysed in the past, but only a few 3D structures were investigated. Analytical formulas to calculate mechanical behaviour for 3D re-entrant structures were introduced by Choi and Lakes [50]. 3D structures of the rotating units [51] and nodule-fibril model [52] were also developed. Introduction of additive manufacturing techniques enables different and new 3D auxetic structures to be fabricated [53] and [54]. Interlocking hexagon models [55] are low porosity structures, which also exhibit auxetic behaviour. Auxetic yarns can find useful applications in composites and textiles [56].

\section{FABRICATION}

Structural auxetic materials can be made from a variety of metals or polymers using different manufacturing procedures. First manufactured auxetic material was re-entrant structure produced by Lakes in 1987 from conventional polymer foam [22]. This procedure is based on triaxial compression and heat treatment of the polymer foam, and was further developed for producing bigger specimens [57]. Similar procedures using solvent instead of heat treatment were also developed [58] with the added advantage that the auxetic foams can be transformed back to the conventional form.

Fabrication of the UHMWPE microporous polymers is done in the following steps: powder compaction, sintering and extrusion. The process is similar in case of the PTFE microporous polymers where the sintered part is rapidly stretched in the axial direction instead of being extruded [25].

Two different molecular design approaches are used to produce organic (molecular) auxetic materials: liquid crystal polymers (LCP) [30], [31] and [59], and three-dimensional tessellated polymer networks [15].

Large auxetic re-entrant honeycomb specimens can be produced with Kevlar fabric and epoxy using the Kirigami manufacturing process [60].

Additive manufacturing technologies offer new manufacturing procedure to make large parts and structures with complex geometries from various metals and plastics [53] and [61], which can be optimised using modern computational tools [41] and [62].

\section{MECHANICAL PROPERTIES}

The effect of Poisson's ratio on mechanical behaviour of an isotropic material can be derived from Eq. (1), with the Young's modulus assumed to be constant [63]:

$$
G=K \frac{3(1-2 v)}{2(1+v)}
$$

where $G$ is the shear modulus (material response to shear stress), $K$ is bulk modulus (material response to volumetric stress) and $v$ is Poisson's ratio.

From Eq. (1) it can be seen that materials with a Poisson's ratio approaching 0.5 (i.e. rubber) readily undergo shear deflections but resist volumetric deformations. When Poisson's ratio approaches the negative limit of -1 for isotropic materials, the shear modulus approaches infinite value and the material 
preserves the shape during loading - material is strong in shear but easy to deform. At this point it must be pointed out that these relationships are valid only for isotropic materials, since in the case of anisotropic materials the bounds on Poisson's ratio are larger, theoretically $-\infty<v<\infty$ [63].

During elastic deformations auxetic materials do not preserve the volume: in the case of tensile deformations the volume of the material increases and vice-versa. This applies to the deformation behaviour before the material reaches yield stress and thereafter the material preserves the volume reached at yield, since the Poisson's ratio does not affect the deformation behaviour during material yielding.

Auxetic materials with Poisson's ratio near minus 1 resist indentation better than conventional materials, because the indentation resistance is inversely proportional to $\left(1-v^{2}\right)$. Enhanced indentation resistance has been proven through investigation of polymeric [64], metallic [65] foams and microporous polymers [66]. In case of impact, non-auxetic materials "flow" away from the impact area, while they "flow" towards the impact zone in case of auxetic materials. This makes the auxetic materials more dense at the impact zone and therefore more resistant to indentation [67].

The characterisation of the mechanical behaviour different auxetic structures has so far been carried out mainly using analytical methods and compressive or tensile testing to determine Poisson's ratio, Young's modulus and energy absorption capabilities [68]. Three-point bending tests were also performed on different structures manufactured by the rapid prototyping [69], electron beam melting (EBM) [70] and Directionally Reinforced Integrated Singleyarn (DIRIS) concept [48]. Dynamic tests of auxetic materials were performed using indentation of the cylinder and ball [64], and, ballistic tests [71].

Experimentally determined values of Poisson's ratio and Young's modulus for different auxetic materials are shown in Table 1. The listed values are the maximum values measured in specimens with different porosities and at different strains [23] and [53].

From Table 1 it can be seen that almost all of the experimentally determined values for the Poisson's ratios in different materials and structures lie in the range from minus 0.6 to minus 1.2 . In only a few cases are values smaller than minus 1.2 , because of material anisotropy. Values of the Young's modulus are given in lesser number of sources than Poisson's ratio, but it can be seen that structures produced with electron beam melting (EBM) methods from Ti6Al4V alloy are very stiff in comparison with any other material, but they are also very brittle because of the production method [75].

Table 1. Mechanical properties of different auxetic materials

\begin{tabular}{|c|c|c|c|}
\hline \multicolumn{2}{|l|}{ Material } & \multirow{2}{*}{$\begin{array}{c}\text { Poisson's } \\
\text { ratio [-] }\end{array}$} & \multirow{2}{*}{$\begin{array}{c}\begin{array}{c}\text { Young's } \\
\text { modulus } \\
{[\mathrm{MPa}]}\end{array} \\
0.072\end{array}$} \\
\hline \multirow{3}{*}{$\begin{array}{l}\text { Transform. conventional } \\
\text { open-cell foam }\end{array}$} & [22] & & \\
\hline & [50] & -0.8 & - \\
\hline & {$[57]$} & -0.82 & - \\
\hline Re-entrant copper foam [72] & [72] and [73] & -0.39 & 30 \\
\hline Re-entrant silicon rubber foam & [73] & -0.25 & 26 \\
\hline PTFE & [23] & -12 & 0.15 \\
\hline UHMWPE & [25] & -1.24 & - \\
\hline \multirow{2}{*}{ 6-chiral } & [35] & $\sim-1$ & - \\
\hline & {$[36]$} & -0.81 & 19.46 \\
\hline \multirow{2}{*}{$\begin{array}{l}\text { Anti } \\
\text { 4-chiral }\end{array}$} & \multirow{2}{*}{ [36] } & -0.98 & 3.11 \\
\hline & & -0.26 & 7.08 \\
\hline Anti 4-chiral & [69] & -1.831 & 5.374 \\
\hline Missing rib & [34] & -0.6 & - \\
\hline Polypropylene film & {$[74]$} & -1.12 & 340 \\
\hline \multirow{2}{*}{ Structures produced with EBM } & [53] & -0.4 & $\sim 8000$ \\
\hline & [75] & $-1,899$ & 5085.3 \\
\hline 3D printed re-entrant lattice & [54] & -1.18 & - \\
\hline Square array with voids & {$[32]$} & -0.73 & - \\
\hline Hierarchical honeycomb & [76] & -0.5 & - \\
\hline Rotating squares film & [77] & -0.963 & - \\
\hline
\end{tabular}

\section{APPLICATIONS}

The auxetic materials have improved the shear performance (increased shear modulus) [78], damping, sound [79] (also with control of bands [80]) and energy absorption [64] and [71] of structural components, which makes them particularly useful for many special applications.

They are being increasingly used in body and vehicle armour applications in sandwich plates for ballistic protection in combination with other materials [81] and [82] fiber composites for greater pull-out resistance (applied tension pull-out force causes increase of cross section area), increased sensitivity piezoelectric composites, new kinds of fasteners, which transversally contract when pushed into a socket (compression load) and expand when attempted to be removed (tension load) [72], flexible pads to reduce impact forces upon small (elbow) and large objects (leg, human torso) [63] which can also be used for sports applications [83], more comfortable textiles with reduced clothing pressure, medical devices (especially bandages) and fashion 
applications [84] and [85], promising and interesting medical application of auxetic materials such as in stents [77]. Very interesting applications in automotive and aerospace engineering are also in double curved sandwich structures, where the advantage of some auxetic material plates to deform in a convex shape (synclastic curvature) is exploited [22] and [86]. Also the out-of-plane strength and stiffness of the auxetic core materials are maximized, since the ribs are always aligned normal to the curved surface [49]. Another interesting application in aerospace engineering shows morphing wings using auxetic structures [87].

There are some examples where auxetic materials are used for thermal protection in aerospace applications (pyrolytic graphite) and vanes for aircraft turbine engines (large single crystals of Ni3Al) [88].

\section{CONCLUSIONS}

The paper gives an overview of fabrication, characterisation, properties and current applications of existing auxetic cellular materials with monotonous internal cellular structure. The response of auxetic materials to dynamic impact loading conditions at different strain rates is not yet sufficiently characterised and needs to be further investigated.

New advanced additive manufacturing techniques provide means to fabricate the next generation of auxetic materials with functionally graded porosity, which can be adapted to the requirements of a particular engineering application by computational simulations and optimization techniques. Such specifically designed internal cellular structure of auxetic materials provides the best desired mechanical response to particular loading conditions. This response can for example result in constant deceleration of impacting projectile or constant reaction force on structures, which is very useful for different applications in defence engineering and crashworthiness.

The auxetic cellular materials and structures show huge potential to become important lightweight structural materials of the future with further development of additive manufacturing technologies or with introduction of some new, more cost effective manufacturing techniques.

\section{ACKNOWLEDGEMENTS}

The paper was produced within the framework of research programme P2-063 entitled "Design of Porous Structures", which is financed by the Slovenian Research Agency "ARRS”.

\section{REFERENCES}

[1] Gibson, L.J., Ashby, M.F. (1997). Cellular Solids: Structure and Properties. Cambridge University Press, Cambridge, D0I:10.1017/CB09781139878326.

[2] Ashby, M.F., Evans, A., Fleck, N., Gibson, L.J., Hutchinson, J.W., Wadley, H.N. (2000). Metal Foams: A Design Guide. Elsevier Science, Burlington.

[3] Banhart, J. (2001). Manufacture, characterisation and application of cellular metals and metal foams. Progress in Materials Science, vol. 46, no. 6, p. 559-632, Dol:10.1016/ S0079-6425(00)00002-5.

[4] Schwartz, D.S., Shih, D.S., Evans, A.G., Wadley, H.N.G. (1998). Porous and cellular materials for structural applications. Materials Research Society Symposium Proceedings, vol. 521.

[5] Duarte, I., Vesenjak, M., Krstulović-Opara, L., Ren, Z. (2015). Static and dynamic axial crush performance of in-situ foamfilled tubes. Composite Structures, vol. 124, p. 128-39, DOI:10.1016/j.compstruct.2015.01.014.

[6] Tanaka, S., Hokamoto, K., Irie, S., Okano, T., Ren, Z., Vesenjak, M., Itoh, S. (2011). High-velocity impact experiment of aluminum foam sample using powder gun. Measurement, vol. 44, no. 10, p. 2185-2189, D0l:10.1016/j. measurement.2011.07.018.

[7] Vesenjak, M., Kovačič, A., Tane, M., Borovinšek, M., Nakajima, H., Ren, Z. (2012). Compressive properties of lotus-type porous iron. Computational Materials Science, vol. 65, p. 37 43, D0I:10.1016/j.commatsci.2012.07.004.

[8] Vesenjak, M., Hokamoto, K., Matsumoto, S., Marumo, Y., Ren, Z. (2016). Uni-directional porous metal fabricated by rolling of copper sheet and explosive compaction. Materials Letters, vol. 170, p. 39-43, D0I:10.1016/j.matlet.2016.01.143.

[9] Sanders, W.S., Gibson, L.J. (2003). Mechanics of BCC and FCC hollow-sphere foams. Materials Science and Engineering: A, vol. 352, no. 1-2, p. 150-161, Dol:10.1016/S09215093(02)00890-0.

[10] Vesenjak, M., Fiedler, T., Ren, Z., Öchsner, A. (2009). Dynamic behaviour of metallic hollow sphere structures. Öechsner, A., Augustin, C. (eds.). Multifunctional Metallic Hollow Sphere Structures, p. 137-158, Springer-Verlag, Berlin, Heidelberg, DOI:10.1007/978-3-642-00491-9_8.

[11] Stöbener, K., Baumeister, J., Rausch, G., Rausch, M. (2005). Forming metal foams by simpler methods for cheaper solutions. Metal Powder Report, vol. 60, no. 1, p. 12-14, 16, D0I:10.1016/S0026-0657(05)00316-4.

[12] Vesenjak, M., Gačnik, F., Krstulović-Opara, L., Ren, Z. (2011). Behavior of composite advanced pore morphology foam. Journal of Composite Materials, vol. 45, no. 26, p. 2823-2831, DOI:10.1177/0021998311410489.

[13] Sulong, M.A., Vesenjak, M., Belova, I.V., Murch, G.E., Fiedler, T. (2014). Compressive properties of advanced pore morphology (APM) foam elements. Materials Science and Engineering: A, vol. 607, p. 498-504, D0l:10.1016/j.msea.2014.04.037.

[14] Fung, Y.C. (1965). Foundations of Solid Mechanics. PrenticeHall, Englewood Cliffs.

[15] Evans, K.E., Nkansah, M.A., Hutchinson, I.J., Rogers, S.C. (1991). Molecular Network Design. Nature, vol. 353, p. 124, DOI:10.1038/353124a0. 
[16] Yeganeh-Haeri, A., Weidner, D.J., Parise, J.B. (1992). Elasticity of a-cristobalite: A silicon dioxide with a negative Poisson's ratio. Science, vol. 257, no. 5070 p. 650-652, Dol:10.1126/ science.257.5070.650.

[17] Lees, C., Vincent, J.F., Hillerton, J.E. (1991). Poisson's ratio in skin. Bio-Medical Materials and Engineering, vol. 1, no. 1, p. 19-23, DOl:10.3233/BME-1991-1104.

[18] Voigt, W. (1928). Lehrbuch der Kristallphysik (mit Ausschluss der Kristalloptik). B.G. Teubner, Leipzig, Berlin.

[19] Muto, K., Bailey, R.W., Mitchell, K.J. (1963). Special requirements for the design of nuclear power stations to withstand earthquakes. Proceedings of the Institution of Mechanical Engineers, vol. 177, no, 1, p. 155-203, DOI:10.1243/PIME_PROC_1963_177_018_02.

[20] Almgren, R.F. (1985). An isotropic three-dimensional structure with Poisson's ratio=-1. Journal of Elasticity, vol. 15, no. 4, p. 427-430, DOI:10.1007/BF00042531.

[21] Gibson, L.J., Ashby, M.F., Schajer, G.S., Robertson, C.I. (1982). The mechanics of two-dimensional cellular material. Proceedings of the Royal Society A, no. 382, p. 25-45, D0l:10.1098/rspa.1982.0087.

[22] Lakes, R. (1987). Foam Structures with a Negative Poisson's Ratio. Science, vol. 235, no. 4792, p. 1038-1040, DOI:10.1126/science.235.4792.1038.

[23] Caddock, B.D., Evans, K.E. (1989). Microporous materials with negative Poisson's ratios. I. Microstructure and mechanical properties. Journal of Physics D: Applied Physics, vol. 22, no. 12, p. 1877-1882, D0I:10.1088/0022-3727/22/12/012.

[24] Evans, K.E., Caddock, B.D. (1989). Microporous materials with negative Poisson's ratios. II. Mechanisms and interpretation. Journal of Physics D. Applied Physics, vol. 22, p. 1883-1887, DOI:10.1088/0022-3727/22/12/013.

[25] Alderson, K.L., Evans, K.E. (1992). The fabrication of microporous polyethylene having a negative Poisson's ratio. Polymer, vol. 33, no. 20, p. 4435-8, D0l:10.1016/00323861(92)90294-7.

[26] Milton, G.W. (1992). Composite materials with poisson's ratios close to -1 . Journal of the Mechanics and Physics of Solids, vol. 40, no. 5, p. 1105-1137, D0l:10.1016/00225096(92)90063-8.

[27] Grima, J.N., Evans, K.E. (2000). Auxetic behavior from rotating squares. Journal of Materials Science Letters, vol. 19, no. 17, p. 1563-1565, DOI:10.1023/A:1006781224002.

[28] Masters, I.G., Evans, K.E. (1996). Models for the elastic deformation of honeycombs. Composite Structures, vol. 35, no. 4, p. 403-422, D0I:10.1016/S0263-8223(96)00054-2.

[29] Grima, J.N., Alderson, A., Evans, K.E. (2004). Negative Poisson'S ratios from rotating rectangles. Computational Methods in Science and Technology, vol. 10, no. 2, p. 137 145, DOI:10.12921/cmst.2004.10.02.137-145.

[30] Grima, J.N., Alderson, A., Evans, K.E. (2005). Auxetic behaviour from rotating rigid units. Physica Status Solidi (B), vol. 242, no. 3, p. 561-575, DOI:10.1002/pssb.200460376.

[31] Grima, J.N., Zammit, V., Gatt, R., Alderson, A., Evans, K.E. (2007). Auxetic behaviour from rotating semi-rigid units. Physica Status Solidi (B), vol. 244, no. 3, p. 866-882, DOl:10.1002/pssb.200572706.
[32] Taylor, M., Francesconi, L., Gerendás, M., Shanian, A., Carson, C., Bertoldi, K. (2013). Low porosity metallic periodic structures with negative Poisson's ratio. Advanced Materials, vol. 26, no. 15, p. 2365-2370, DOI:10.1002/adma.201304464.

[33] Smith, C.W., Grima, J.N., Evans, K.E. (2000). A novel mechanism for generating auxetic behaviour in reticulated foams: missing rib foam model. Acta Materialia, vol. 48, no. 17, p. 4349-4356, D0I:10.1016/S1359-6454(00)00269-X.

[34] Gaspar, N., Ren, X.J., Smith, C.W., Grima, J.N., Evans, K.E. (2005). Novel honeycombs with auxetic behaviour. Acta Materialia, vol. 53, no. 8, p. 2439-2445, Dol:10.1016/j. actamat.2005.02.006.

[35] Prall, D., Lakes, R.S. (1997). Properties of a chiral honeycomb with a poisson's ratio of -1 . International Journal of Mechanical Sciences, vol. 39, no. 3, p. 305-314, D0l:10.1016/ S0020-7403(96)00025-2.

[36] Alderson, A., Alderson, K.L., Attard, D., Evans, K.E., Gatt, R., Grima, J.N., Miller, W., Ravirala, N., Smith, C.W., Zied, K. (2010). Elastic constants of 3-, 4- and 6-connected chiral and anti-chiral honeycombs subject to uniaxial in-plane loading. Composites Science and Technology, vol. 70, no. 7, p. 10421048, D0I:10.1016/j.compscitech.2009.07.009.

[37] Theocaris, P.S., Stavroulakis, G.E., Panagiotopoulos, P.D. (1997). Negative Poisson's ratios in composites with starshaped inclusions: a numerical homogenization approach. Archive of Applied Mechanics, vol. 67, no. 4, p. 274-286, DOI:10.1007/s004190050117.

[38] Larsen, U.D., Sigmund, O., Bouwstra, S. (1997). Design and fabrication of compliant micromechanisms and structures with negative Poisson's ratio. Journal of Microelectromechanical Systems, vol. 6, no. 2, p. 99-106, D0I:10.1109/84.585787.

[39] Shan, S., Kang, S.H., Zhao, Z., Fang, L., Bertoldi, K. (2015). Design of planar isotropic negative Poisson's ratio structures. Extreme Mechanics Letters, vol. 4, p. 96-102, Dol:10.1016/j. eml.2015.05.002.

[40] Cho, Y., Shin, J.-H., Costa, A., Kim, T.A., Kunin, V., Li, J., Lee, S.Y., Yang, S., Han, H.N., Choi, I.-S., Srolovitz, D.J. (2014). Engineering the shape and structure of materials by fractal cut. Proceedings of the National Academy of Sciences of the United States of America, vol. 111, no. 49, p. 17390-17395, DOl:10.1073/pnas.1417276111.

[41] Körner, C., Liebold-Ribeiro, Y. (2015). A systematic approach to identify cellular auxetic materials. Smart Materials and Structures, vol. 24, no. 2, p. 025013, Dol:10.1088/09641726/24/2/025013.

[42] Alderson, A., Evans, K.E. (1995). Microstructural modelling of auxetic microporous polymers. Journal of Materials Science, vol. 30, no. 13, p. 3319-3332, D0l:10.1007/BF00349875.

[43] Alderson, A., Evans, K.E. (1997). Modelling concurrent deformation mechanisms in auxetic microporous polymers. Journal of Materials Science, vol. 32, no. 11, p. 2797-2809, D0I:10.1023/A:1018660130501.

[44] Grima, J.N., Williams, J.J., Evans, K.E. (2005). Networked calix[4]arene polymers with unusual mechanical properties. Chemical Communications, vol. 1, p. 4065-4067, DOl:10.1039/b505839b. 
[45] He, C., Liu, P., Griffin, A.C. (1998). Toward Negative Poisson Ratio Polymers through Molecular Design. Macromolecules, vol. 31, no. 9, p. 3145-3147, Dol:10.1021/ma970787m.

[46] Yao, Y.T., Uzun, M., Patel, I. (2011). Workings of auxetic nano-materials. Journal of Achievements in Materials and Manufacturing Engineering, vol. 49, no. 2, p. 585-593.

[47] Clarke, J.F., Duckett, R.A., Hine, P.J., Hutchinson, I.J., Ward, I.M. (1994). Negative Poisson's ratios in angle-ply laminates: theory and experiment. Composites, vol. 25, no. 9, p. 863868, Dol:10.1016/0010-4361(94)90027-2.

[48] Michelis, P., Spitas, V. (2010). Numerical and experimental analysis of a triangular auxetic core made of CFR-PEEK using the Directionally Reinforced Integrated Single-yarn (DIRIS) architecture. Composites Science and Technology, vol. 70, no. 7, p. 1064-1071, D0l:10.1016/j.compscitech.2010.01.013.

[49] Alderson, A., Alderson, K.L. (2007). Auxetic materials. Proceedings of the Institution of Mechanical Engineers, Part G: Journal of Aerospace Engineering, vol. 221, no. 4, p. 565575, DOI: 10.1243/09544100JAER0185.

[50] Choi, J.B., Lakes, R.S. (1995). Nonlinear analysis of the Poisson's Ratio in negative Poisson's Ratio foams. Journal of Composite Materials, vol. 29, no. 1, p. 113-128, DOI:10.1177/002199839502900106.

[51] Alderson, A., Evans, K.E. (2001). Rotation and dilation deformation mechanisms for auxetic behaviour in the $\alpha$-cristobalite tetrahedral framework structure. Physics and Chemistry of Minerals, vol. 28, no. 10, p. 711-718, DOl:10.1007/s002690100209.

[52] Gaspar, N., Smith, C.W., Alderson, A., Grima, J.N., Evans, K.E. (2011). A generalised three-dimensional tethered-nodule model for auxetic materials. Journal of Materials Science, vol. 46, no. 2, p. 372-384, DOl:10.1007/s10853-010-4846-0.

[53] Schwerdtfeger, J., Heinl, P., Singer, R.F., Körner, C. (2010). Auxetic cellular structures through selective electron beam melting. Physica Status Solidi (B), vol. 247, no. 2, p. 269-272, DOI:10.1002/pssb.200945513.

[54] Critchley, R., Corni, I., Wharton, J.A., Walsh, F.C., Wood, R.J.K., Stokes, K.R. (2013). The preparation of auxetic foams by three-dimensional printing and their characteristics. Advanced Engineering Materials, vol. 15, no. 10, p. 980-985, DOl:10.1002/adem.201300030.

[55] Ravirala, N., Alderson, A., Alderson, K.L. (2007). Interlocking hexagons model for auxetic behaviour. Journal of Materials Science, vol. 42, no. 17, p. 7433-7445, D0I:10.1007/s10853007-1583-0.

[56] Sloan, M.R., Wright, J.R., Evans, K.E. (2011). The helical auxetic yarn - A novel structure for composites and textiles; geometry, manufacture and mechanical properties. Mechanics of Materials, vol. 43, no. 9, p. 476-486, Dol:10.1016/j. mechmat.2011.05.003.

[57] Chan, N., Evans, K.E. (1997). Fabrication methods for auxetic foams. Journal of Materials Science, vol. 32, no. 22, p. 59455953, D0I:10.1023/A:1018606926094.

[58] Grima, J.N., Attard, D., Gatt, R., Cassar, R.N. (2009). A novel process for the manufacture of auxetic foams and for their re-conversion to conventional form. Advanced Engineering Materials, vol. 11, no. 7, p. 533-535, D0l:10.1002/ adem.200800388.
[59] He, C., Liu, P., McMullan, P.J., Griffin, A.C. (2005). Toward molecular auxetics: Main chain liquid crystalline polymers consisting of laterally attached para-quaterphenyls. Physica Status Solidi (B), vol. 242, no. 3, p. 576-584, D0l:10.1002/ pssb.200460393.

[60] Hou, Y., Neville, R., Scarpa, F., Remillat, C., Gu, B., Ruzzene, M. (2014). Graded conventional-auxetic Kirigami sandwich structures: Flatwise compression and edgewise loading. Composites Part B: Engineering, vol. 59, p. 33-42, DOI:10.1016/j.compositesb.2013.10.084.

[61] Heinl, P., Körner, C., Singer, R.F. (2008). Selective electron beam melting of cellular titanium: Mechanical properties. Advanced Engineering Materials, vol. 10, no. 9, p. 882-888, DOI:10.1002/adem.200800137.

[62] Wang, F., Sigmund, O., Jensen, J.S. (2014). Design of materials with prescribed nonlinear properties. Journal of the Mechanics and Physics of Solids, vol. 69, p. 156-174, D0l:10.1016/j. jmps.2014.05.003.

[63] Lakes, R. (1993). Advances in negative Poisson's ratio materials. Advanced Materials, vol. 5, no. 4, p. 293-296, DOI:10.1002/adma.19930050416.

[64] Chan, N., Evans, K.E. (1998). Indentation resilience of conventional and auxetic foams. Journal of Cellular Plastics, vol. 34, no. 3, p. 231-260, Dol:10.1177/0021955X9803400304.

[65] Lakes, R.S., Elms, K. (1993). Indentability of conventional and negative Poisson's ratio foams. Journal of Composite Materials, vol. 27, no. 12, p. 1193-1202, Dol:10.1177/002199839302701203.

[66] Alderson, K.L., Fitzgerald, A., Evans, K.E. (2000). The strain dependent indentation resilience of auxetic microporous polyethylene. Journal of Materials Science, vol. 35, no. 16, p. 4039-4047, Dol:10.1023/A:1004830103411.

[67] Alderson, A. (1999). A triumph of lateral thought. Chemistry and Industry, vol. 10, p. 384-391.

[68] Scarpa, F., Pastorino, P., Garelli, A., Patsias, S., Ruzzene, M. (2005). Auxetic compliant flexible PU foams: static and dynamic properties. Physica Status Solidi (B), vol. 242, no. 3, p. 681-694, D0I:10.1002/pssb.200460386.

[69] Chen, Y.J., Scarpa, F., Liu, Y.J., Leng, J.S. (2013). Elasticity of anti-tetrachiral anisotropic lattices. International Journal of Solids and Structures, vol. 50, no. 6, p. 996-1004, DOI:10.1016/j.jjsolstr.2012.12.004.

[70] Horn, T.J., Harrysson, O.L.A., Marcellin-Little, D.J., West, H.A., Lascelles, B.D.X., Aman, R. (2014). Flexural properties of Ti6Al4V rhombic dodecahedron open cellular structures fabricated with electron beam melting. Additive Manufacturing, vol. 1-4, p. 2-11, Dol:10.1016/J.addma.2014.05.001.

[71] Yang, S., Qi, C., Wang, D., Gao, R., Hu, H., Shu, J. (2013). A comparative study of ballistic resistance of sandwich panels with aluminum foam and auxetic honeycomb cores. Advances in Mechanical Engineering, vol. 5, p. 589216, DOl:10.1155/2013/589216.

[72] Choi, J.B., Lakes, R.S. (1991). Design of a fastener based on negative Poisson's ratio foam. Cellular Polymers, vol. 10, p. 205-212.

[73] Friis, E.A., Lakes, R.S., Park, J.B. (1988). Negative Poisson's ratio polymeric and metallic foams. Journal of Materials 
Science, vol. 23, no. 12, p. 4406-4414, D0l:10.1007/ BF00551939.

[74] Ravirala, N., Alderson, A., Alderson, K.L., Davies, P.J. (2005). Auxetic polypropylene films. Polymer Engineering \& Science, vol. 45, no. 4, p. 517-528, Dol:10.1002/pen.20307.

[75] Yang, L., Harrysson, O., West, H., Cormier, D. (2012). Compressive properties of Ti-6Al-4V auxetic mesh structures made by electron beam melting. Acta Materialia, vol. 60, no. 8, p. 3370-3379, D0l:10.1016/j.actamat.2012.03.015.

[76] Mousanezhad, D., Babaee, S., Ebrahimi, H., Ghosh, R., Hamouda, A.S., Bertoldi, K., Vaziri, A. (2015). Hierarchical honeycomb auxetic metamaterials. Scientific Reports, vol. 5 , p. 18306, DOI:10.1038/srep18306.

[77] Ali, M.N., Busfield, J.J.C., Rehman, I.U. (2014). Auxetic oesophageal stents: structure and mechanical properties. Journal of Materials Science: Materials in Medicine, vol. 25, no. 2, p. 527-553, Dol:10.1007/s10856-013-5067-2.

[78] Yang, W., Li, Z.M., Shi, W., Xie, B.H., Yang, M.B. (2004). On auxetic materials. Journal of Materials Science, vol. 39, no. 10, p. 3269-3279, D0I:10.1023/B:JMSC.0000026928.93231. e.

[79] Scarpa, F., Ciffo, L.G., Yates, J.R. (2004). Dynamic properties of high structural integrity auxetic open cell foam. Smart Materials and Structures, vol. 13, no. 1, p. 49-56, DOI:10.1088/0964-1726/13/1/006.

[80] Krödel, S., Delpero, T., Bergamini, A., Ermanni, P., Kochmann, D.M. (2014). 3D auxetic microlattices with independently controllable acoustic band gaps and quasi-static elastic moduli. Advanced Engineering Materials, vol. 16, no. 4, p. 357-363, DOI:10.1002/adem.201300264.
[81] Imbalzano, G., Tran, P., Ngo, T.D., Lee, P.V.S. (2015). A Numerical Study of Auxetic Composite Panels under Blast Loadings. Composite Structures, vol. 135, p. 339-352, D0l:10.1016/j.compstruct.2015.09.038.

[82] Imbalzano, G., Tran, P., Ngo, T.D., Lee, P. V. (in press). Threedimensional modelling of auxetic sandwich panels for localised impact resistance. Journal of Sandwich Structures and Materials, Dol:10.1177/1099636215618539.

[83] Sanami, M., Ravirala, N., Alderson, K., Alderson, A. (2014). Auxetic materials for sports applications. Procedia Engineering, vol. 72, p. 453-458, D0l:10.1016/j.proeng.2014.06.079.

[84] Wright, J.R., Burns, M.K., James, E., Sloan, M.R., Evans, K.E. (2012). On the design and characterisation of low-stiffness auxetic yarns and fabrics. Textile Research Journal, vol. 82, no. 7, p. 645-654, D0I:10.1177/0040517512436824.

[85] Rant, D., Rijavec, T., Pavko Čuden, A. (2013). Auxetic textiles. Acta Chimica Slovenica, vol. 60, no. 4, p. 715-723.

[86] Evans, K.E. (1991). The design of doubly curved sandwich panels with honeycomb cores. Composite Structures, vol. 17, no. 2, p. 95-111, D0l:10.1016/0263-8223(91)90064-6.

[87] Airoldi, A., Crespi, M., Quaranti, G., Sala, G. (2012). Design of a morphing airfoil with composite chiral structure. Journal of Aircraft, vol. 49, no. 4, p. 1008-1019, D0l:10.2514/1. C031486.

[88] Evans, K.E., Alderson, A. (2000). Auxetic materials: Functional materials and structures from lateral thinking! Advanced Materials, vol. 12, no. 9, p. 617-628, D0I:10.1002/(SICI)15214095(200005)12:9<617::AID-ADMA617>3.0.C0;2-3. 